\title{
Toward Equity under Health System Reform; A Systematic Review
}

\author{
Kamran Bagheri Lankaran, ${ }^{1}$ Hamid Reza Khankeh, ${ }^{2,3}$ Nooshin Zarei, ${ }^{4}$ Mohammad Fararouei, ${ }^{5}$ Zahra
}

Saboori, ${ }^{6}$ and Hassan Joulaei ${ }^{1,{ }^{*}}$

${ }^{1}$ Health Policy Research Center, Institute of Health, Shiraz University of Medical Sciences, Shiraz, Iran

${ }^{2}$ Department of Nursing, University of Social Welfare and Rehabilitation Sciences (USWR), Tehran, Iran

${ }^{3}$ Department of Clinical Science and Education, Karolinska Institutet, Stockholm, Sweden

${ }^{4}$ Shiraz HIV/AIDS Research Center, Institute of Health, Shiraz University of Medical Sciences, Shiraz, Iran

${ }^{5}$ Department of Epidemiology, School of Public Health, Shiraz University of Medical Sciences, Shiraz, Iran

${ }^{6}$ George Washington University Alumnus, Washington DC, USA

"Corresponding author: Hassan Joulaei, Pharm D, MPH, PhD, Health Policy Research Center, Institute of Health, Shiraz University of Medical Sciences, Shiraz, Iran. Tel/Fax: +98-7132309615, E-mail: joulaei_h@yahoo.com

Received 2017 September 04; Accepted 2017 September 06.

\begin{abstract}
Background: To improve health equity, many countries have undergone consistent health sector reforms during the two past decades although most of them still have some challenges ahead.

Objectives: This systematic review aimed to determine the impact of health system reforms on inequities and social determinants of health (SDOH) since the year 2000.

Methods: PubMed, Scopus, and Google Scholar databases were utilized to conduct a literature search of related records from January 2000 to August 2014. Out of 1,559 published articles, 29 were selected according to specified inclusion and exclusion criteria.

Results: Almost all investigated countries have considered financial interventions to address increases in governmental health expenditures and implement universal health coverage. While most countries stressed in-patient or outpatient care, primary care is often disregarded in many health system reforms. Although the aforementioned reforms have been somewhat successful, several socioeconomic groups continue to experience health inequities.

Conclusions: These results illustrate the vital role that socioeconomic and political determinants play in the success of studied reforms. Furthermore, emphasizing primary health care, implementing reforms in a stepwise and well-monitored manner, and utilizing quality control mechanisms can mitigate health inequity.
\end{abstract}

Keywords: Health Sector Reform, Socio-Economic Status, Equity, Utilization

\section{Introduction}

According to the world health organization's report in Rio de Janeiro's conference for social determinants of health, all people hold the right to live with the "highest standards of a healthy life" (1). Health sector reforms (HSR) - defined as purposeful and standard changes in the health sector aiming to improve equity, efficiency, and effectiveness- often assist in reaching such standards by reducing regional socioeconomic inequities and providing equal access to healthcare (2-5). As illustrated in literature, the most notable cause of global health inequities is socioeconomic inequalities among different groups within a society (6). Obviously, various socio-economic classes in each society comprise individuals with different health states, thereby establishing situations that leave certain parts of the population deprived from a healthy and high-quality life.

Health systems are complex because there are no linear relationships between different functions, components, or outcomes; this makes it difficult to evaluate health sector reform with respect to complex outcomes of health system. Yet ever since the 1990s, numerous frameworks have been introduced to analyze reforms and outcomes of health systems (7). Examples of such frameworks include six building blocks, four functions, and control knobs of health systems (7). Of these frameworks, the six building blocks approach is a valuable measure for pinpointing, describing, and prioritizing health system restrictions. It identifies where and why investments have to be focused, what happens as an outcome, and by what measures the changes can be overseen (7).

Over past 20 years, many countries focused on social determinants to reduce health inequities when implementing reformative actions. Most HSRs worked to expand health insurance towards universal health coverage (UHC) (3, 8-10). While many developing and developed countries with HSRs may have been successful in some areas, most countries experienced challenges and barriers. As an example, the Netherlands, (11) the United States, (12) Chile, 
(13) Turkey (14) China, (15) Thailand, (16) South Korea, (17) Brazil, (18) and Iran $(19,20)$ were able to take actions to promote their healthcare services despite the negative consequences.

Hence, this study aimed to utilize the six building blocks framework in determining the impact of HSRs on reducing inequities, particularly with respect to $\mathrm{SDOH}$.

\section{Methods}

Using the population, intervention, comparator, and outcome (PICO) as a reference, the study attempted to answer the following question: what are the effects of HSRs on reducing health inequalities? The setting of this study included nationwide HSRs within the past 15 years that focused on improving health equity, while the target population was healthcare providers affected by those HSRs. Interventions within this study included HSRs of any type that were directed towards reducing health disparities. Pre and post reform health-related indices were evaluated as the measures of interest (comparators). The outcomes of HSRs were determined by comparing health insurance coverage, out of pocket (OOP)/government healthcare expenditures, and quality, access, and utility of health services.

\subsection{Search Strategy and Data Sources}

Based on guidelines set forth for systematic reviews, a comprehensive literature search was conducted for studies with similar research questions $(21,22)$. Protocols and systematic review search took place via different databases including the center for reviews and dissemination, and the Cochrane database of systematic reviews.

The researchers used Scopus, PubMed/Medline, and Google Scholar to find primary and secondary articles/documents published in English between 2000 and 2014. This timeframe was chosen to integrate measurable and recent impacts of HSRs on health indices. Search terms were chosen with respect to the PICO reference that included mesh terms such as "health sector/ system/ care reform", "coverage", "equity", "residence”, "ethnicity", "utility", "gender" and "socio-economic status". Upon entering search phrases into the databases, the document type was set to "article" and the search was completed in "all field". The researchers utilized a protocol recommended by the Preferred Reporting Items for Systematic Reviews and Meta- Analyses (PRISMA) to conduct the search between August 20th and 30th, 2014.

\subsection{Inclusion and Exclusion Criteria}

Documents or articles highlighting health disparitiesfocused HSRs were included in this review. Although the review focused on HSRs that took place after 2000, many articles that referred to HSRs taking place during the mid1990s were also included in the review. Exclusion criteria included studies about HSRs not being focused on equity, those with general explanations of HSRs or sub-national reforms, and those with qualitative designs. Other articles that were excluded were letters to editors, opinions and editorials, and case studies. This review process yielded 1559 articles, 29 of which met the inclusion criteria (Figure 1).

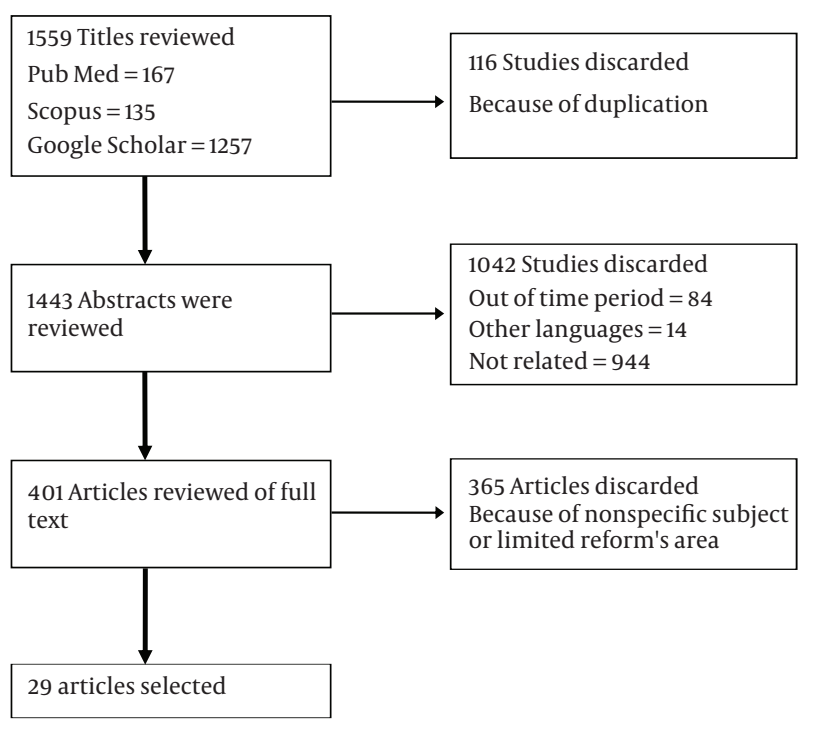

Figure 1. Flow Diagram of the Search Strategy

HSRs can be analyzed using a host of available frameworks, some of which include control knobs, four function, and six building blocks of health systems. As per WHO guidelines, we chose the latter framework to conduct our analysis because it provides insight into specific elements needed by health systems to reach certain milestones (23). The six building blocks approach includes leadership and governance, healthcare financing, medical products and technology, information, health workforce, and health service delivery.

\section{Results}

A closer look at the 29 articles yielded about 21 countries with equity-driven HSRs throughout the aforementioned timeframe. Financial interventions such as increasing insurance coverage and additional government health expenditures were considered by most countries under review. HSRs in countries like the Philippines, Turkey, China, Chile, Kosovo, India, and UAE incorporated more than three building blocks. All HSRs displayed both positive and 
negative outcomes. Table 2 summarizes findings of HSRs and outcomes for each country based on the six building blocks framework.

In general, HSRs aim to enforce equity and efficiency in health care utilization. Most studied reforms utilized strategies in providing UHC and implemented financial interventions focused on expanding insurance coverage. Despite the implemented strategies, all HSRs have been associated with nuisances and challenges. Our findings suggest that many characteristics are effective in the success rate of HSRs, which are elaborated in the sections below:

First, countries must consider the socioeconomic and political context as well as health sector reform. Consistent with our results, global evidence indicates that applying a host of health equity-driven strategies without paying attention to socio-economic and political factors, has led to failures in HSRs in many developing countries. A notable example of this factor is China's overwhelming economic growth rate over the past few decades, leading to sustainable health care investment and HSR aiming at improving health status of its target population (Table 2). Yet, this notable economic growth rate intensified rural and urban health disparities, which demonstrates the impact of China's HSRs on equity-related outcomes $(24,25)$. Similarly, articles regarding HSRs in Chile point out to evident ongoing healthcare utilization disparities because of financial barriers and social factors such as education level, health literacy, and residency area (13, 26-28). In addition, introducing payment reforms to the Rural Health program in Georgia has attempted to offset health inequities; inequalities still remain among different socioeconomic groups, as seen in higher healthcare utilization among urban populations due to higher incomes when compared to rural ones (29, 30). In addition, the impact of socio-political context on HSRs is evident within the complex turmoil in Syria, where the civil war has diminished previous HSR success and resident living conditions (31). In contrast, the key to success in Turkey's HSR was political stability (14). Finally, gender and socio-economic disparities in Turkey have diminished HSR goals directed towards health equity, particularly in the most underprivileged provinces (32). For example, low SES women in Turkey experience heightened health problems because of interpersonal violence and discrimination. As is evident in Table 1, HSRs among most countries under study have led to positive economic growth rates (33-35). Only Iran and Mali exhibited negative growth rates during their HSRs; both also had intermittent positive growth. HSRs in Latin America, Kosovo, and the Philippines were associated with positive economic growth and shifting towards democratization (36-38). Mexico has displayed continued interest in combining various political stakeholders in favor of its reform
(39). In sum, while the aforementioned cases illustrate the impact of health inequities on HSRs, health sector-related characteristics must also be considered in evaluating reforms $(25,29,40)$ and.

The second important factor is focusing on strengthening primary health care (PHC) within health sector reforms. According to WHO, implementing PHC is the most beneficial in promoting equal access to a plethora of health services (41). There is an inter-connection between economic and social development with primary health care (42). Although PHC expands social benefits to the underprivileged, many countries have allocated resources to establish inpatient and outpatient care (3). More attention has been devoted to strengthening PHC in Armenia, India, Kosovo, Turkey, and China. Although these countries have achieved many successes with regard to expanding access to primary health care, in order to gain optimum results from this policy they still need more investment and infrastructures (15). Despite the anticipated benefits, the US displays shortcomings in implementing PHC (43). This lack of attention is associated with increased costs and health equity challenges when promoting health insurance coverage. The promotion of a simple and effective National Health Network system in Iran has led to improvements in health indicators and increased PHC access (43). Yet, the steady digression of stakeholders' interests towards treatment-oriented approaches has weakened this successful prevention-oriented system over time. However, we must note that an emphasis on PHC does not necessarily mean neglecting inpatient and outpatient care. Experiences from the Philippines and India confirm that neglecting this level of health services may deprive those with low SES access to comprehensive care $(36,44$, 45). A stronger PHC infrastructure is generally indicative of continuity, comprehensive, and need-based care (46).

Taking quality of healthcare as well as quantity is the third contributing factor to improving health equity. The definition of equitable access emphasizes both quality and quantity (47). Since policy makers often aim to expand the short-term financial coverage of services for the underprivileged, many reforms often neglect quality of health services. While Mexico has developed beneficial qualitydriven programs, it still has to bridge the gap of health disparities and outcomes between socio-economic groups (48). Despite the fact that Philippines' government has attempted to implement quality-driven strategies, a WHO review indicates inadequate quality care due to lack of coordination and incentives. Even though hospitals and private practices have established protocol for quality care, the lack of licensing standards diminishes the quality of primary health centers (49). Another successful reform is seen in Turkey's efforts for comprehensive health system 
improvements. Yet, this change has not led to uniform improvements in quality of care among sectors and regions (50). Many countries, such as the United Arab Emirates, have implemented a master plan to promote health equity among low socioeconomic groups (51). While this may seem like a good short-term remedy, long-term impacts may deepen disparities between socioeconomic levels.

The fourth contributing factor to effective equitydriven reform is establishing a robust monitoring system from the beginning. Almost all studied reforms exhibit imperfect and discontinuous monitoring systems throughout different time points. Many countries did not display any sort of comprehensive monitoring system, even years after the reforms. As an example, China's health information system (HIS) has only been implemented for certain diseases and therefore, it lacks comprehensiveness and the ability to monitor diverse health outcomes (52). One of the main problems of Iran's health system is also weaknesses in implementing an inconsistent information system (53). Similarly, South Africa also lacks robust information management system regarding both supply and demand (54). Ambiguities in access and improvement in health outcomes among Georgian and Abu Dhabi health care systems post reform indicate the lack of a comprehensive health information system $(30,51)$. In addition, fragmentations within India's monitoring system obscure the impact of HSR on health outcomes (45). Yet, HSRs in Mexico and Turkey have led to the establishment of continuous and effective monitoring systems, thereby leading to better care coordination over time. Comprehensive information systems provide policy makers with readily available and high quality evidence that is necessary for effective decision-making $(41,55)$.

Finally implementing stepwise reforms instead of big reforms could better target health equity in developing countries with sparse resources and inconsistent infrastructure. While both are purposeful in nature, small reforms occur incrementally while big reforms occur strategically. Certain factors are necessary to implement a successful big reform. Such factors include coherent and reliable leadership, political support for reforms, sustainable healthcare financing, governmental stability, and skilled health workforce (42). Our findings indicate that HSRs among most countries experienced gentle and insufficient increases in health sector financing, particularly within the 2012 - 2013 window. As seen in Table 1, out-ofpocket health expenditures comprise over $20 \%$ of spending within $73 \%$ of the countries under study, which further confirms a shortage of financial investment in these countries. Therefore, the magnitude of the reforms should be adopted with required resources in long term to avoid stopping programs. Positive HSR outcomes due to long- term planning and sustainable management are evident within experiences of Chile, China, Mexico, and Turkey. Experiences in Syria (56) and Kosovo (37) indicate that there is no one formula that can drive HSRs or from within. With minimal examples of success, such findings indicate that big reforms are not appropriate to implement in developing countries. Finally, for those countries with stronger infrastructures, decentralization is an effective approach to improve health equity (42).

While this review utilizes a novel strategy to evaluate health equity-focused HSRs, there are some limitations. First, the literature search was limited to peer-reviewed articles and documents published in English. Second, we excluded information within the gray literature due to limited access to international journals.

\section{Conclusions}

Based upon the results of this study, we suggest five pillars in achieving HSR goals: 1) Taking into consideration the political and socioeconomic context and health sector reforms in order to ensure sustainability, 2) Prioritizing and strengthening PHC over inpatient and outpatient care, 3) Emphasizing healthcare quality along with financial investments to enhance comprehensive care for all socioeconomic groups, 4) Establishing a robust monitoring system early on to ensure appropriate resource allocation and prioritization for HSR interventions and 5) Promoting changes in infrastructure, along with enforcing incremental HSRs.

\section{Acknowledgments}

The authors appreciate Shiraz University of Medical Sciences for its financial contribution. The authors wish to thank all participants for their time and patience.

\section{Footnotes}

Authors' Contribution: Study concept and design, Kamran Bagheri Lankarani; interpretation of data, Hassan Joulaei; drafting the manuscript, Nooshin Zarei, Hamid Reza Khankeh; critical revision of the manuscript, Zahra Saboori.

Conflict of Interests: To their best knowledge, the authors have no conflicts of interests in publishing this manuscript.

Funding/Support: Research deputy of Shiraz University of Medical Sciences supported the study (Grant number 93/7386) 
Table 1. Trends of Public Health Expenditure, OOP, and Economic Growth Rate Among Countries of Interest Over Time

\begin{tabular}{|c|c|c|c|c|c|c|c|c|c|}
\hline \multirow[t]{3}{*}{ Country } & \multicolumn{3}{|c|}{ Per Capita Expenditure on Health (PPP int. S) (57) } & \multicolumn{3}{|c|}{ GDP Growth (34) } & \multicolumn{3}{|c|}{ Out of Pocket (35) } \\
\hline & \multicolumn{9}{|c|}{ Year } \\
\hline & 2000 & 2012 & 2013 & 2011 & 2012 & 2013 & 2000 & 2012 & 2013 \\
\hline China & 50 & 323 & 360 & 9.5 & 7.8 & 7.7 & 59 & 34.3 & 33.9 \\
\hline Iran & 162 & 492 & 577 & 3.9 & -6.6 & -1.9 & 56.2 & 52.5 & 52.1 \\
\hline Chile & 248 & 768 & 795 & 5.8 & 5.5 & 4.2 & 41.9 & 32.4 & 31.7 \\
\hline us & 2074 & 4153 & 4307 & 1.6 & 2.3 & 2.2 & 14.9 & 11.9 & 11.8 \\
\hline Turkey & 275 & 745 & 815 & 8.8 & 2.1 & 4.2 & 27.6 & 15.4 & 15 \\
\hline South Africa & 254 & 528 & 543 & 3.2 & 2.2 & 2.2 & 13 & 7.1 & 7.1 \\
\hline Indonesia & 31 & 108 & 114 & 6.2 & 6.0 & 5.6 & 46.5 & 45.3 & 45.8 \\
\hline Rwanda & 10 & 93 & 95 & 7.9 & 8.8 & 4.7 & 24.8 & 18.8 & 18.4 \\
\hline Vietnam & 31 & 124 & 129 & 6.2 & 5.2 & 5.4 & 66 & 48.8 & 49.4 \\
\hline Ghana & 41 & 133 & 130 & 14.0 & 9.3 & 7.3 & 31.8 & 29.1 & 36.2 \\
\hline India & 24 & 60 & 69 & 6.6 & 5.1 & 6.9 & 67.1 & 60.6 & 58.2 \\
\hline Kenya & 31 & 40 & 42 & 6.1 & 4.6 & 5.7 & 43.2 & 45.3 & 44.6 \\
\hline Mali & 23 & 38 & 49 & 2.7 & -0.4 & 2.1 & 66.5 & 60.9 & 60.1 \\
\hline Nigeria & 34 & 55.6 & 49.4 & 4.9 & 4.3 & 5.4 & 61.7 & 65.8 & 72.9 \\
\hline The Philippines & 51 & 82 & 91 & 3.7 & 6.8 & 7.2 & 40.5 & 57.6 & 56.7 \\
\hline UAE & 1444 & 1188 & 1570 & 4.9 & 4.7 & 5.2 & 16.1 & 19.5 & 18.8 \\
\hline Syria & 63 & 77 & 78 & - & - & - & 59.6 & 53.9 & 53.9 \\
\hline Malaysia & 211 & 494 & 514 & 5.2 & 5.6 & 4.7 & 33.7 & 34.9 & 36.1 \\
\hline Mexico & 237 & 550 & 549 & 4.0 & 4.0 & 1.4 & 50.9 & 44.1 & 44.1 \\
\hline Kosovo* & - & - & - & - & - & - & - & - & - \\
\hline Armenia & - & 33 & 34 & 4.7 & 7.2 & 3.5 & & 70.5 & 73.8 \\
\hline Georgia & 29 & 116 & 150 & 7.2 & 6.2 & 3.3 & 82.5 & 64.7 & 61.9 \\
\hline
\end{tabular}

\section{References}

1. World Health Organization. Closing the gap: policy into practice on social determinants of health: discussion paper. 2011

2. Gwatkin DR. The need for equity-oriented health sector reforms. Int $J$ Epidemiol. 2001;30(4):720-3. [PubMed: 11511591].

3. World Health Organization. World health report 2000: health system performance.; 2000.

4. Frenk J, Gomez-Dantes O, Knaul FM. The democratization of health in Mexico: financial innovations for universal coverage. Bull World Health Organ. 2009;87(7):542-8. doi: 10.2471/BLT.08.053199. [PubMed: 19649369].

5. Almeida C, Travassos C, Porto S, Labra ME. Health sector reform in Brazil: a case study of inequity. IntJ Health Serv. 2000;30(1):129-62. doi: 10.2190/NDGW-C2DP-GNF8-HEW8. [PubMed: 10707303].

6. Health 21: The health for all policy framework for the WHO European Region.J Adv Nurs. 1999;30(2):280. [PubMed: 10484702].

7. Hsiao W, Burgess C, editors. Building on health systems frameworks for developing a common approach to health systems strengthening. 2009; Washington, DC. Prepared for the World Bank, the Global Fund and the GAVI Alliance Technical Workshop on Health Systems Strengthening.

8. Chen M, Chen W, Zhao Y. New evidence on financing equity in China's health care reform-a case study on Gansu province, China. BMC Health Serv Res. 2012;12:466. doi: 10.1186/1472-6963-12-466. [PubMed: 23244513].

9. Wagstaff A, Lindelow M, Wang S, Zhang S. Reforming China's rural health system. World Bank Publications; 2009.

10. Frenz P, Delgado I, Kaufman JS, Harper S. Achieving effective universal health coverage with equity: evidence from Chile. Health Policy Plan. 2014;29(6):717-31. doi: 10.1093/heapol/czt054. [PubMed: 23921988].
11. den Exter A. Health system reforms in the Netherlands: from public to private and its effects on equal access to health care. Eur J Health Law. 2010;17(3):223-33. doi: 10.1163/157180910X504810. [PubMed: 20666285].

12. Maruthappu M, Ologunde R, Gunarajasingam A. Is Health Care a Right? Health Reforms in the USA and their Impact Upon the Concept of Care. Ann Med Surg (Lond). 2013;2(1):15-7. doi: 10.1016/S20490801(13)70021-9. [PubMed: 25973184].

13. Bastias G, Pantoja T, Leisewitz T, Zarate V. Health care reform in Chile. CMAJ. 2008;179(12):1289-92. doi:10.1503/cmaj.071843. [PubMed: 19047610].

14. Atun R, Aydin S, Chakraborty S, Sumer S, Aran M, Gurol I, et al. Universal health coverage in Turkey: enhancement of equity. Lancet. 2013;382(9886):65-99. doi: 10.1016/S0140-6736(13)61051-X. [PubMed: 23810020].

15. Tang S, Meng Q, Chen L, Bekedam H, Evans T, Whitehead M. Tackling the challenges to health equity in China. Lancet. 2008;372(9648):1493501. doi: 10.1016/S0140-6736(08)61364-1. [PubMed: 18930531].

16. Patcharanarumol W. Presentation on Universal Health Care Coverage: Thailand Experience. International Health Policy Program Thailand. 2008.

17. Anderson GF. Universal health care coverage in Korea. Health Aff(Millwood). 1989;8(2):24-34. doi: 10.1377/hlthaff.8.2.24. [PubMed: 2744694].

18. Elias PE, Cohn A. Health reform in Brazil: lessons to consider. Am J Public Health. 2003;93(1):44-8. doi: 10.2105/AJPH.93.1.44. [PubMed: 12511382].

19. Davari M, Haycox A, Walley T. Health care financing in iran; is privatization a good solution? Iran J Public Health. 2012;41(7):14-23. [PubMed: 23113205].

20. Takian A, Doshmangir L, Rashidian A. Implementing family physician programme in rural Iran: exploring the role of an existing primary 
health care network. Fam Pract. 2013;30(5):551-9. doi: 10.1093/fampra/cmt025. [PubMed: 23788202].

21. Tacconelli E. Systematic reviews: CRD's guidance for undertaking reviews in health care. Lancet Infect Dis. 2010;10(4):226. doi: 10.1016/s1473-3099(10)70065-7.

22. Higgins JPT, Green S. Cochrane handbook for systematic reviews of interventions. Wiley Online Library; 2008.

23. World Health Organization . Monitoring the building blocks of health systems: a handbook of indicators and their measurement strategies. Geneva, Switzerland: World Health Organization; 2010.

24. Wang T, Zeng R. Addressing inequalities in China's health service. Lancet. 2015;386(10002):1441. doi: 10.1016/S0140-6736(15)00402-X. [PubMed: 26466037].

25. Xu L, Wang Y, Collins CD, Tang S. Urban health insurance reform and coverage in China using data from National Health Services Surveys in 1998 and 2003. BMCHealth Serv Res. 2007;7:37. doi:10.1186/1472-69637-37. [PubMed: 17335584].

26. Burrows J. Inequalities and healthcare reform in Chile: equity of what? J Med Ethics. 2008;34(9):e13. doi: 10.1136/jme.2007.022715. [PubMed: 18757613].

27. Nunez A, Chi C. Equity in health care utilization in Chile. Int J Equity Health. 2013;12:58. doi: 10.1186/1475-9276-12-58. [PubMed: 23937894].

28. Paraje G, Vasquez F. Health equity in an unequal country: the use of medical services in Chile. Int J Equity Health. 2012;11:81. doi: 10.1186/1475-9276-11-81. [PubMed: 23249481].

29. Unger JP, De Paepe P, Cantuarias GS, Herrera OA. Chile's neoliberal health reform: an assessment and a critique. PLoS Med. 2008;5(4):e79. doi: 10.1371/journal.pmed.0050079. [PubMed: 18384231].

30. Gotsadze G, Zoidze A, Vasadze O. Reform strategies in Georgia and their impact on health care provision in rural areas: evidence from a household survey. Soc Sci Med. 2005;60(4):809-21. doi: 10.1016/j.socscimed.2004.06.017. [PubMed: 15571898].

31. Kherallah M, Sahloul Z, Jamil G, Alahfez T, Eddin KD. Health care in Syria before and during the crisis. Avicenna J Med. 2012;2(3):51. doi: 10.4103/2231-0770.102275.

32. Tatar M, Kanavos P. Health care reform in Turkey. Health Policy Dev. 2006;12(1):20.

33. World Health Organization. Health expenditure per capita, all countries, selected years Estimates by country 2013. Available from: http: //apps.who.int/gho/data/node.main.78?lang=en.

34. The World Bank . GDP per capita (current US\$) 2015. Available from: http://data.worldbank.org/indicator/NY.GDP.PCAP.CD.

35. World Health Organization . Out-of-pocket expenditure on health as a percentage of private expenditure on health (US\$) 2015. Available from: http://www.who.int/gho/health_financing/out_pocket_ expenditure/en/.

36. Obermann K, Jowett MR, Taleon JD, Mercado MC. Lessons for health care reform from the less developed world: the case of the Philippines.EurJ Health Econ. 2008;9(4):343-9. doi: 10.1007/s10198-007-00812. [PubMed: 17952477].

37. Percival V, Sondorp E. A case study of health sector reform in Kosovo. Confl Health. 2010;4:7. doi: 10.1186/1752-1505-4-7. [PubMed: 20398389].

38. Atun R, de Andrade LO, Almeida G, Cotlear D, Dmytraczenko T, Frenz $P$, et al. Health-system reform and universal health coverage in Latin America. Lancet. 2015;385(9974):1230-47. doi: 10.1016/S01406736(14)61646-9. [PubMed: 25458725].

39. Knaul FM, Frenk J. Health insurance in Mexico: achieving universal coverage through structural reform. Health Aff (Millwood). 2005;24(6):1467-76. doi: 10.1377/hlthaff.24.6.1467. [PubMed: 16284018].

40. Ali Jadoo SA, Aljunid SM, Sulku SN, Nur AM. Turkish health system reform from the people's perspective: a cross sectional study. BMC Health Serv Res. 2014;14:30. doi: 10.1186/1472-6963-14-30. [PubMed: 24447374].

41. World Health Organization . The world health report 2013: Research for universal health coverage. Geneva: WHO; 2013.
42. Faye A, Bob M, Fall A, Fall C. [Primary health care and the millennium development goals]. Med Sante Trop. 2012;22(1):6-8. doi: 10.1684/mst.2012.0003. [PubMed: 22868717].

43. Joulaei H, Lankarani KB, Shahbazi M. Iranian and American health professionals working together to address health disparities in Mississippi Delta based on Iran's Health House model. Arch Iran Med. 2012;15(6):378-80. [PubMed: 22642250].

44. Ghosh S. Health sector reforms and changes in prevalence of untreated morbidity, choice of healthcare providers among the poor and rural population in India. Int J Health Policy Manag. 2014;2(3):12530. doi: 10.15171/ijhpm.2014.32. [PubMed: 24757689].

45. Rout SK. Health sector reforms in orissa: The disconnecting paths.J Health Manag. 2010;12(3):305-25.

46. Schafer WL, Boerma WG, Murante AM, Sixma HJ, Schellevis FG, Groenewegen PP. Assessing the potential for improvement of primary care in 34 countries: a cross-sectional survey. Bull World Health Organ. 2015;93(3):161-8. doi: 10.2471/BLT.14.140368. [PubMed: 25883409].

47. Oliver A, Mossialos E. Equity of access to health care: outlining the foundations for action.JEpidemiol Community Health. 2004;58(8):6558. doi: 10.1136/jech.2003.017731. [PubMed: 15252067].

48. Moher D, Liberati A, Tetzlaff J, Altman DG, Prisma Group . Preferred reporting items for systematic reviews and meta-analyses: the PRISMA statement. PLoS Med. 2009;6(7):e1000097. doi: 10.1371/journal.pmed.1000097. [PubMed: 19621072].

49. World Health Organization . The Philippines health system review. Manila: WHO Regional Office for the Western Pacific; 2011.

50. Sulku SN. The health sector reforms and the efficiency of public hospitals in Turkey: provincial markets. Eur J Public Health 2012;22(5):634-8. doi: 10.1093/eurpub/ckr163. [PubMed: 22075550].

51. Koornneef EJ, Robben PB, Al Seiari MB, Al Siksek Z. Health system reform in the Emirate of Abu Dhabi, United Arab Emirates. Health Policy. 2012;108(2-3):115-21. doi:10.1016/j.healthpol.2012.08.026. [PubMed: 22998984]

52. Brixi H, Mu Y, Targa B, Hipgrave D. Engaging sub-national governments in addressing health equities: challenges and opportunities in China's health system reform. Health Policy Plan. 2013;28(8):809-24. doi: 10.1093/heapol/czs120. [PubMed: 23221008].

53. Heshmati B, Joulaei H. Iran's health-care system in transition. Lancet 2016;387(10013):29-30. doi: 10.1016/S0140-6736(15)01297-0. [PubMed: 26766344]

54. Ruff B, Mzimba M, Hendrie S, Broomberg J. Reflections on health-care reforms in South Africa.J Public Health Policy. 2011;32 Suppl 1:S184-92. doi: 10.1057/jphp.2011.31. [PubMed: 21730990].

55. Oliver K, Innvar S, Lorenc T, Woodman J, Thomas J. A systematic review of barriers to and facilitators of the use of evidence by policymakers. BMC Health Serv Res. 2014;14:2. doi: 10.1186/1472-6963-14-2. [PubMed: 24383766].

56. Sen K, al Faisal W. Syria neoliberal reforms in health sector financing Embedding unequal access? Soc Med. 2012;6(3):171-82.

57. Xu K, Saksena P, Jowett M, Indikadahena C, Kutzin J, Evans DB. Exploring the thresholds of health expenditure for protection against financial risk. World health report; 2010.

58. Sulku SN. The impacts of health care reforms on the efficiency of the Turkish public hospitals: Provincial markets. 2011

59. van den Heever AM. The role of insurance in the achievement of universal coverage within a developing country context: South Africa as a case study. BMC Public Health. 2012;12 Suppl 1:S5. doi: 10.1186/14712458-12-S1-S5. [PubMed: 22992410].

60. Lagomarsino G, Garabrant A, Adyas A, Muga R, Otoo N. Moving towards universal health coverage: health insurance reforms in nine developing countries in Africa and Asia. Lancet. 2012;380(9845):93343. doi: 10.1016/S0140-6736(12)61147-7. [PubMed: 22959390].

61. Yu CP, Whynes DK, Sach TH. Reform towards National Health Insurance in Malaysia: the equity implications. Health Policy. 2011;100(23):256-63. doi: 10.1016/j.healthpol.2010.10.018. [PubMed: 21129808]. 
62. Arredondo A, Orozco E. Equity, governance and financing after health care reform: lessons from Mexico. Int J Health Plann Manage. 2008;23(1):37-49. doi:10.1002/hpm.913. [PubMed: 18000949].

63. Gakidou E, Lozano R, Gonzalez-Pier E, Abbott-Klafter J, Barofsky JT, Bryson-Cahn C, et al. Assessing the effect of the 2001-06 Mexican health reform: an interim report card. Lancet. 2006;368(9550):192035. doi: 10.1016/S0140-6736(06)69568-8. [PubMed: 17126725].

64. Jowett M, Danielyan E. Is there a role for user charges? Thoughts on health system reform in Armenia. Bull World Health Organ. 2010;88(6):472-3. doi: 10.2471/BLT.09.074765. [PubMed: 20539867]. 


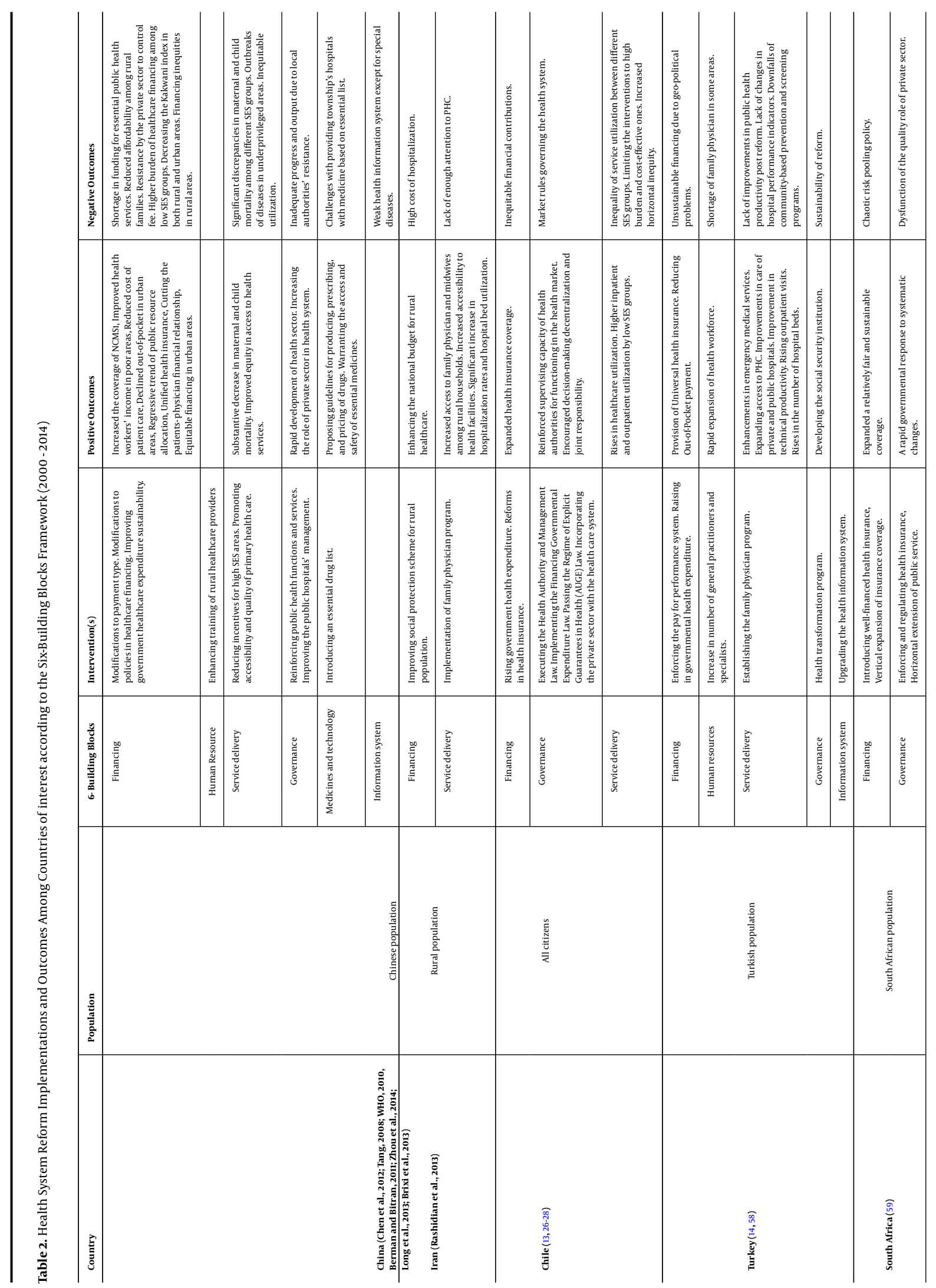




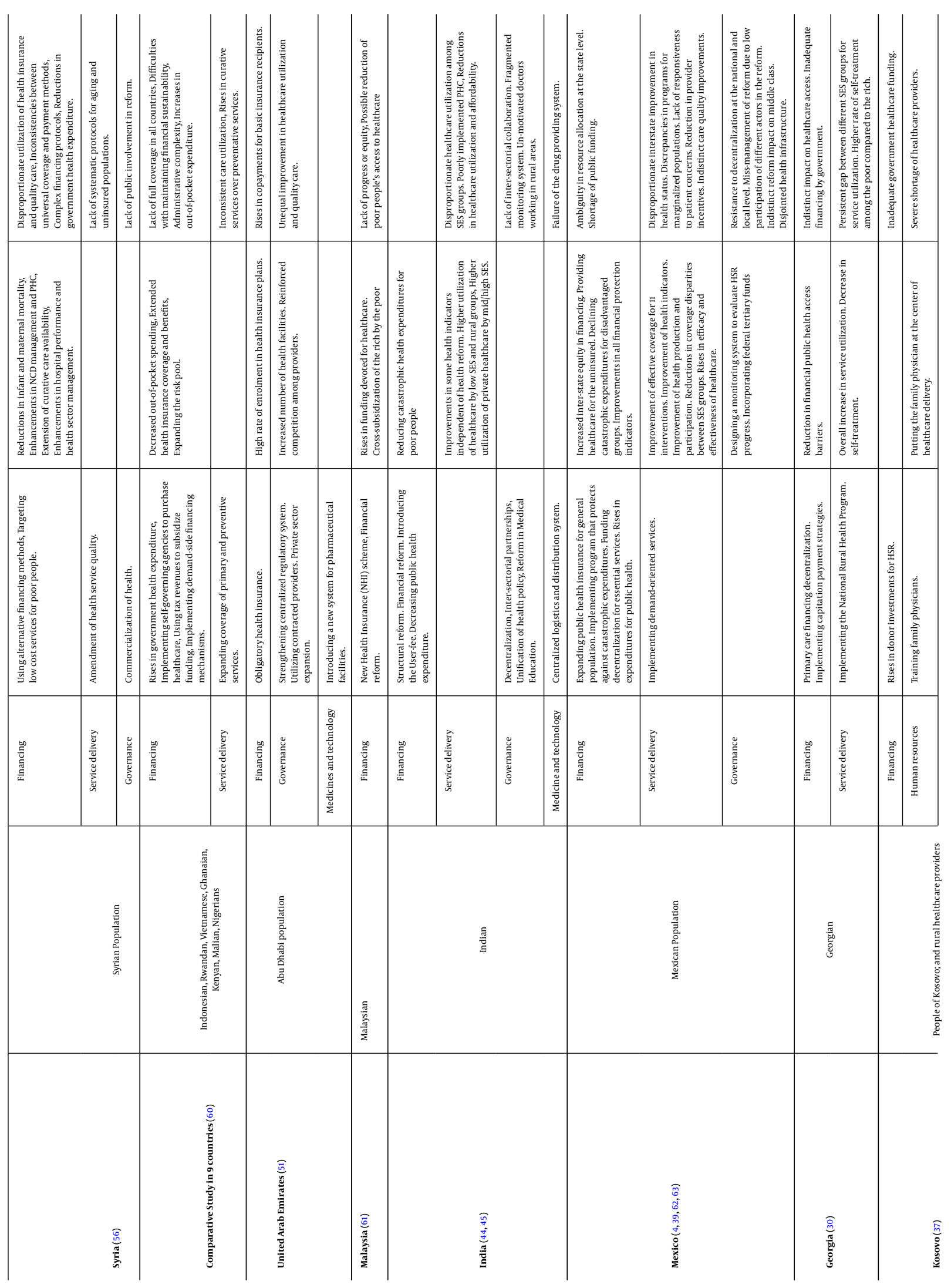




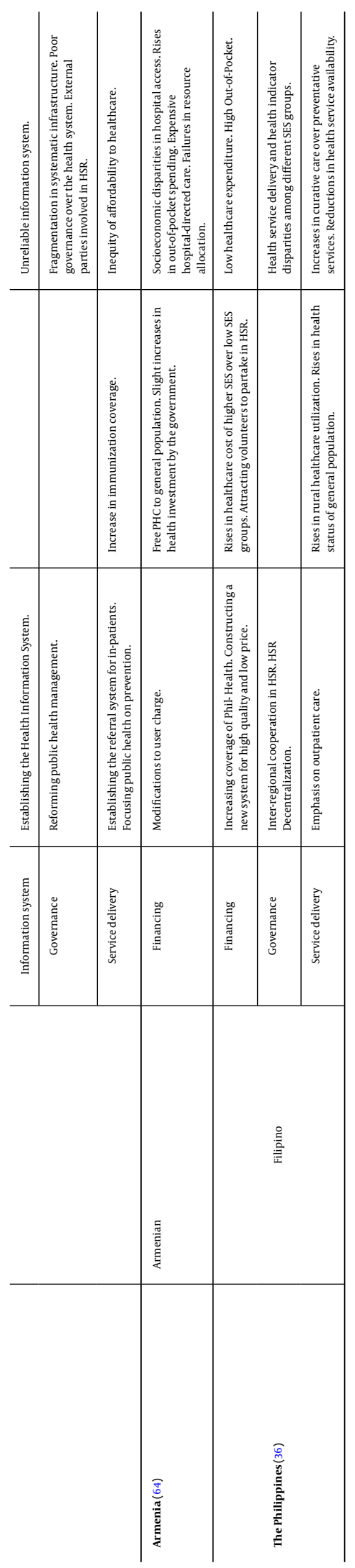

10 